\title{
Response of winter wheat grain yield and water use efficiency to deficit irrigation in the North China Plain
}

\author{
Huifang Han', Yujie Ren², Chao Gao², Zhenxing Yan², Quanqi Li²* \\ ${ }^{1}$ State Key Laboratory of Crop Biology, Shandong Key Laboratory of Crop Biology, Shandong Agricultural University, Tai'an, Shandong, \\ 271018, P.R. China, ${ }^{2}$ College of Water Conservancy and Civil Engineering, Shandong Agricultural University, Tai'an, Shandong, 271018, P.R. \\ China
}

\section{A B S TRACT}

\begin{abstract}
Water resources in the North China Plain (NCP) are limited, so it's in urgent need to optimize deficit by irrigation for sustainable winter wheat production in this area. Winter wheat grain yield (GY), contribution of dry matter (DM) remobilization to GY (CDMRG), and water use efficiency (WUE) were investigated in NCP. Compared with non-irrigation treatment, irrigated with $60 \mathrm{~mm}$ each at the winter wheat jointing stage (JS) and heading stage (HS) achieved reasonable winter wheat GY and WUE. Compared with irrigation with $120 \mathrm{~mm}$ only at JS and irrigation with $40 \mathrm{~mm}$ each at JS, HS, and milking stage (MS) of winter wheat, irrigation with $60 \mathrm{~mm}$ each at JS and HS provided the highest CDMRG, which resulted to the highest GY and WUE; this result was mainly due to a significant increase of the spike numbers (SN) per $\mathrm{m}^{2}$. The results suggest that in the NCP, in order to achieve reasonable GY and WUE, winter wheat should be irrigated with $60 \mathrm{~mm}$ each at JS and HS.
\end{abstract}

Keywords: Aboveground dry matter; Soil water content; Evapotranspiration; Precipitation; Growing season

\section{INTRODUCTION}

The NCP, covers an area of more than 1.5 million hectare. In this region, winter common wheat is the most important cultivated crop, and produces about $50 \%$ of the total winter wheat GY (Tian et al., 2013). Many results indicated that the water requirement over the growing season of winter wheat was more than $400 \mathrm{~mm}$ (Bian et al., 2016; Zhao et al., 2013; Zhou et al., 2011); however, during the growing season of winter wheat, precipitation ranges from 100 to $180 \mathrm{~mm}$. Therefore, water is the most important limiting factor for the production of winter wheat.

In order to increase winter wheat GY in the NCP, additional irrigation is required. For the shortage of surface water, groundwater has become the most important source of irrigation water (Sun et al., 2010). In recent years, 70\% of irrigation water is used for winter wheat ( $\mathrm{Li}$ et al., 2005). With the increase of winter wheat cultivated land, groundwater levels are persistently declining, and resulting in serious environmental problems, it has already been the widest funnel-shaped zone of groundwater in the world
(Guo et al., 2010). Current limitation of water resources is threatening winter wheat productivity, and this trend is expected to increase in the future. Hence, farmers are obliged to deal with this problem by implementing sustainable agricultural water managements aimed at maintaining winter wheat GY with less water. In order to increase irrigation water productivity in arid area, many researchers found that deficit irrigation was an effective measure (James et al., 2012; Neal et al., 2012; Romulus et al., 2012).

Deficit irrigation has been successfully used on potatoes (Wang et al., 2009), tomatoes (Cristina et al., 2011), cotton (Fazlullah et al., 2013), rice (Soundharajan and Sudheer, 2009), forages (Neal et al., 2012; Neal et al., 2011), corn (Nader et al., 2010), oilseed rape (Istanbulluoglu et al., 2010), onion (Igbadun et al., 2012), and peach trees (Bartolomeo et al., 2007). It was also used in cereal crops and showed that it improved yield performance in winter wheat (Zhang et al., 2006). However, compared with full irrigation, many results showed that winter wheat GY in deficit irrigation decreased (Xue et al., 2003; Abolfazl and Hossein 2007).

\footnotetext{
${ }^{*}$ Corresponding author:

Quanqi Li, College of Water Conservancy and Civil Engineering, Shandong Agricultural University, Tai'an, Shandong, 271018, P.R. China.

E-mail: quanqili@sdau.edu.cn

Received: 15 February 2017; Revised: 23 December 2017; Accepted: 29 December 2017; Published Online: 08 January 2018
} 
Deficit irrigation is very easy to be applied in field, it has been raised and attracted considerable interest in recent years. This irrigation method may improve winter wheat WUE (Blum, 2007; Dong et al., 2011), but GY could be decreased. In China, $80 \%$ of the food is produced on irrigated farmland and this plays an important role in feeding the 1.3 billion populations (Wu et al., 2006). About $50 \%$ of winter wheat GY is produced in the NCP. If GY will decrease significantly under deficit irrigation, it will not ensure food security of China. Hence, the only method to maintain winter wheat production in this area is to develop water-saving agriculture and improve WUE without a significant GY reduction. Rao et al. (2013) showed that deficit irrigation subject to $75 \%$ of soil water deficit can maximize wheat yield, and Li et al. (2013) found that reasonable winter wheat GY and WUE could be achieved under the condition of deficit irrigation. Hence, we hypothesized that there maybe a considerable scope for raising winter wheat $G Y$ by the effect of deficit irrigation in the NCP.

In this paper, field experiments have been conducted on winter wheat in 3 typical regions in the NCP to investigate the improved WUE and GY of winter wheat and provide scientific basis and useful guidelines to farmers on how to optimize deficit irrigation technology for sustainable winter wheat production.

\section{MATERIALS AND METHODS}

\section{Experimental site}

During 2002-2003 winter wheat growing season, the experiment was conducted at the Yucheng Comprehensive Experimental Station of Chinese Academy of Science $\left(36^{\circ} 57^{\prime} \mathrm{N}, 116^{\circ} 38^{\prime} \mathrm{E}\right)$. The mean annual precipitation at the Station is $590 \mathrm{~mm}$, of which approximately $38 \%$ falls during the winter wheat growing season. The soil at the Station is classified as sandy loam soil with an organic matter content (OMC) of approximately $0.5 \%$, soil organic carbon content was $8.9 \mathrm{~g} / \mathrm{kg}$, the level of rapidly available phosphorous (RAP) was $12.6 \mathrm{mg} / \mathrm{kg}$, potassium was $171.0 \mathrm{mg} / \mathrm{kg}$, nitrogen was $68.3 \mathrm{mg} / \mathrm{kg}$, and field capacity (FC) and wilting point of $25.1 \%$ and $8.0 \%$ by volume, respectively. During 2004-2005 and 2005-2006 growing seasons of winter wheat, the experiment was conducted at the Taian Agronomy Station of Shandong Agricultural University $\left(36^{\circ} 10^{\prime} \mathrm{N}, 117^{\circ} 09^{\prime} \mathrm{E}\right)$, the mean annual precipitation is $700 \mathrm{~mm}$, of which approximately $34.8 \%$ falls during the winter wheat growing season. The soil at this experimental site is classified as loam soil with an OMC of approximately $1.4 \%$, soil organic carbon was $10.7 \mathrm{~g} / \mathrm{kg}$, the level of RAP was $13.2 \mathrm{mg} / \mathrm{kg}$, potassium was $78.5 \mathrm{mg} / \mathrm{kg}$, nitrogen was $83.1 \mathrm{mg} / \mathrm{kg}$, and FC and wilting point of $25.8 \%$ and $7.7 \%$ by volume, respectively. During 2006-2007 and 2007-2008 growing seasons of winter wheat, the experiment was conducted at the Luancheng Experimental Station of Chinese Academy of Science $\left(37^{\circ} 50^{\prime} \mathrm{N}, 114^{\circ} 40^{\prime} \mathrm{E}\right)$, the mean annual precipitation at the Station is $485 \mathrm{~mm}$, of which approximately $30 \%$ falls during the growing season of winter wheat. The soil at the experimental site is classified as loam soil with an OMC of approximately $1.2 \%$, soil organic carbon was $10.7 \mathrm{~g} / \mathrm{kg}$, the level of RAP was $15 \mathrm{mg} / \mathrm{kg}$, potassium was $150 \mathrm{mg} / \mathrm{kg}$, nitrogen was $80 \mathrm{mg} / \mathrm{kg}$, and FC and wilting point of $36.4 \%$ and $9.6 \%$ by volume, respectively. At Yucheng and Taian, the experiments were conducted in pool cultures. The areas of the pool cultures at Yucheng and Taian were 6.7 and $8.0 \mathrm{~m}^{2}$, respectively, at a depth of $1.5 \mathrm{~m}$; the pool cultures were enclosed with a concrete wall, and the bottom surfaces of the plots were not sealed. The plot surface was $15.0 \mathrm{~cm}$ above the ground surface from all sides to prevent runoff and subsurface movement of water between the plots. At Luancheng, the experiment was conducted at field condition, and the area of the irrigation plots was $16 \mathrm{~m}^{2}$, and there were $15-\mathrm{cm}$ beds around the plots. Between 2 adjacent irrigation plots, there was a $1.5 \mathrm{~m}$ wide zone without irrigation to minimize the effects of 2 adjacent plots on each other. All the agronomy practices during the trial were officially approved by the above three stations.

\section{Experimental design Preliminary experiment and experiment 1}

Preliminary experiment was conducted at Yucheng during one growing season 2002-2003. Experiment 1 was conducted at Taian during two growing seasons 2002/032003/04. The following 4 irrigation regimes were applied for both experiments during the winter wheat growing season: non-irrigation (T0), irrigated $60 \mathrm{~mm}$ at JS (T1), irrigated $60 \mathrm{~mm}$ each at JS and HS (T2), and irrigated 60 $\mathrm{mm}$ each at JS, HS, and MS (T3).

\section{Experiment 2}

Based on the results obtained in experiment 1, during the growing season of winter wheat, irrigated $120 \mathrm{~mm}$ could get reasonable GY and WUE; hence, at Luancheng, the following 3 irrigation regimes were applied during the winter wheat growing season: irrigated $120 \mathrm{~mm}$ only at JS (I1), irrigated $60 \mathrm{~mm}$ each at JS and HS (I2), and irrigated $40 \mathrm{~mm}$ each at JS, HS, and MS (I3).

In the three experiments, at the time of sowing, $30.0 \mathrm{~g} \mathrm{~m}^{-2}$ of triple superphosphate, $30.0 \mathrm{~g} \mathrm{~m}^{-2}$ of urea, and $7.5 \mathrm{~g} \mathrm{~m}^{-2}$ of potassium chloride were applied to the soil. Water was supplied from a pump outlet to the experiment sites by using plastic pipes, a flow meter was used to measure the amount of water supplied. Each of the three 
independent experiments was conducted in triplicate, using a randomized block design.

The winter wheat varieties 93-52, 8049, and 9204 were used at Yucheng, Taian, and Luancheng, respectively, all of them were not drought-tolerant varieties.

In preliminary experiment during 2002 year winter wheat cultivars were sown on October 4 and was harvested on June 6 2003. Irrigation was applied at JS on April 6, at HS on April 30 and at MS on May 16.

In the first experiment cultivars were sown on 6 and 11 October during 2004 and 2005 years and was harvested on June 7 and 9 2005, 2006 year. Irrigation was applied at JS on April 7-2004/05 and on April 6-2005/06, at HS on April 27-2004/05 and April 28-2005/06 and at MS on May 14-2004/05 and on May 16-2005/06.

In the second experiment, wheat cultivars were sown on 12 and 17 October 2006 and 2007 years and was harvested on 11, 12 June 2007 and 2008, respectively. Irrigation was applied at JS on April 7, 9, at HS on April 30, 29, and at MS on May 17, 21 in 2006-2007, and 2007-2008 growing seasons of winter wheat, respectively. At the time of sowing, $30.0 \mathrm{~g} \mathrm{~m}^{-2}$ of triple superphosphate, $30.0 \mathrm{~g} \mathrm{~m}^{-2}$ of urea, and $7.5 \mathrm{~g} \mathrm{~m}^{-2}$ of potassium chloride were applied to the soil.

\section{Measurements}

\section{Grain yield and yield components}

When the plants had reached maturity, 1-m stretches of 2 rows were selected at random in each experimental plots to measure SN, 1000-kernel weight, and GY. The plants were harvested manually and air-dried. An additional 20 plants were harvested to determine the kernel numbers per spike.

\section{Volumetric soil water content}

The volumetric soil water content (SWC) of the cores obtained at every $10 \mathrm{~cm}$ down to $120 \mathrm{~cm}$ at Yucheng and Taian and $180 \mathrm{~cm}$ at Luancheng in the planting zone was measured by a CNC503B neutron moisture meter (Super Energy. Nuclear Technology Ltd., Beijing, China). The SWC in the top $20 \mathrm{~cm}$ soil layer was measured by oven-drying method. Measurements were performed at approximately 7 -day interval. Before and after precipitation and irrigation, additional measurements were performed.

\section{Evapotranspiration}

Evapotranspiration of winter wheat was calculated using the following equation (Zhao et al., 2013):

$\mathrm{ET}=\mathrm{I}+\mathrm{P}-\mathrm{R}-\mathrm{D}-\mathrm{SW}$
In equation 1, ET (mm), the evapotranspiration; I (mm), the amount of irrigation water; P (mm), precipitation, which was measured from the weather station at the sites by using a standard rain gauge; $\mathrm{R}$ ( $\mathrm{mm}$ ), the surface runoff, which was assumed as not significant since concrete slabs or beds were placed around each plot; D (mm), the downward flux below the crop root zone, which was ignored since SWC indicated that drainage at the sites were negligible; and SW (mm), the change in water storage in the soil profile exploited by plant roots.

\section{Water use efficiency}

WUE was defined as follows (He et al., 2009 ):

$\mathrm{WUE}=\frac{Y}{E T}$

In equation $2, \mathrm{Y}\left(\mathrm{kg} / \mathrm{m}^{2}\right)$, the winter wheat GY; ET (mm), the growing-season evapotranspiration derived from equation 1.

\section{Contribution of DM remobilization to grain yield}

Contribution of DM remobilization to GY (CDMRG) was calculated using the following equation (Li et al., 2010):

CDMRG $=\frac{D M R}{Y} \times 100$

In equation 3, DMR $\left(\mathrm{g} / \mathrm{m}^{2}\right)$, the DM remobilization to $\mathrm{GY}$, is the difference between aboveground DM at flowering and maturity; $\mathrm{Y}\left(\mathrm{g} / \mathrm{m}^{2}\right)$, the GY, was measured at maturity.

\section{Data analysis}

The date of the experiment 2 was analyzed for variance using the analysis of variance (ANOVA) of SAS software package (SAS Institute, 1996). For ANOVA, $\alpha=0.05$ was set as the level of significance to determine whether significant differences existed among the yearly means of the various treatments. Multiple comparisons were performed for significant effects with the least significant difference (LSD) test at $\alpha=0.05$.

\section{RESULTS}

\section{Precipitation}

Precipitation during the 5 growing seasons of winter wheat was presented in Table 1 . Based on the annual mean precipitation during the growing seasons of winter wheat, 2002-2003 and 2006-2007 were classified as moderate growing seasons, 2004-2005 and 2005-2006 were classified as dry growing seasons, and 2007-2008 was classified as humid growing season, respectively. 
Han, et al:: Yield and water use efficiency of wheat

Table 1: Precipitation during the growing seasons of winter wheat $(\mathrm{mm})$

\begin{tabular}{lccccccccccc}
\hline Experimental sites & Growing seasons & Oct ${ }^{\text {a }}$ & Nov & Dec & Jan & Feb & Mar & Apr & May & Jun ${ }^{\text {b }}$ & Total \\
\hline Yucheng & $2002-2003$ & 8.7 & 20.0 & 3.3 & 23.9 & 12.4 & 31.8 & 63.2 & 44.1 & 14.8 & 222.2 \\
Taian & $2004-2005$ & 2.2 & 27.0 & 4.0 & 0.0 & 14.5 & 0.0 & 51.8 & 94.4 & 0.0 & 193.3 \\
& $2005-2006$ & 4.6 & 5.4 & 3.8 & 4.7 & 7.8 & 0.0 & 23.5 & 77.0 & 0.0 & 126.8 \\
Luancheng & $2006-2007$ & 0.6 & 17.1 & 3.9 & 0.0 & 1.4 & 52.1 & 16.7 & 48.2 & 0.0 & 140.0 \\
& $2007-2008$ & 1.3 & 86.0 & 2.8 & 1.4 & 0.0 & 0.0 & 40.0 & 61.9 & 82.8 & 276.2 \\
\hline
\end{tabular}

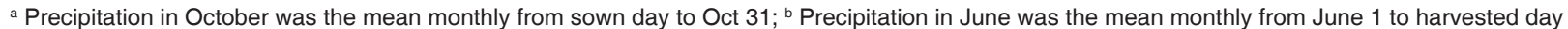

\section{Preliminary experiment and Experiment 1 Grain yield}

As shown in Fig. 1, in both dry and moderate growing seasons, winter wheat GY increased with irrigation amount increased. In 2002-2003 winter wheat growing season, the GY was significantly higher in $\mathrm{T} 2$ and $\mathrm{T} 3$ than in $\mathrm{T} 0$ and $\mathrm{T} 1$; however, the difference between $\mathrm{T} 2$ and $\mathrm{T} 3$ was not significant. Compared with T0, the GY in T1, T2, and T3 was increased by $29.7,71.5$, and $89.6 \mathrm{~g} / \mathrm{m}^{2}$, respectively. In both 2004-2005 and 2005-2006 growing seasons of winter wheat, the GY was significantly higher in T1, T2, and T3 than in $\mathrm{T} 0$, and the GY was significantly higher in $\mathrm{T} 2$ than in T1; however, there were no significant differences between T2 and T3 in the both growing seasons. In 2004-2005 winter wheat growing season, compared with T0, the GY in T1, T2, and T3 were increased by 46.1, 76.7, and 83.8 $\mathrm{g} / \mathrm{m}^{2}$, and in 2005-2006 winter wheat growing season, were $76.2,123.2$, and $136.7 \mathrm{~g} / \mathrm{m}^{2}$, respectively. Hence, the potential irrigation production decreased with irrigation amount increased. The results indicate that irrigated 120 $\mathrm{mm}$ during the growing seasons of winter wheat could result in reasonable GY.

\section{Water use efficiency}

Fig. 2 presented the WUE in 2002-2003, 2004-2005 and 2005-2006 growing seasons of winter wheat. In 2002-2003, the WUE was significantly higher in T1, T2, and $\mathrm{T} 3$ than in $\mathrm{T} 0$, and $\mathrm{T} 2$ attained the highest WUE; however, it was not significantly different than that in T1 and T3. In both 2004-2005 and 2005-2006 growing seasons of winter wheat, the trend was opposite, the WUE was declined with irrigation amount increased. In the both growing seasons, the WUE was significantly lower in T1, T2, and T3 than in T0, and the WUE was significantly higher in T2 than in T3. However, in 2005-2006 winter wheat growing season, the difference between $\mathrm{T} 1$ and $\mathrm{T} 2$ was not significant.

The GY was not significantly higher in T3 than in T2; however, its WUE was significantly lower. Hence, in both dry and moderate growing seasons of winter wheat, combined with winter wheat GY and WUE as a whole, it is suggests that winter wheat should be irrigated $120 \mathrm{~mm}$, which will achieve reasonable GY and WUE.

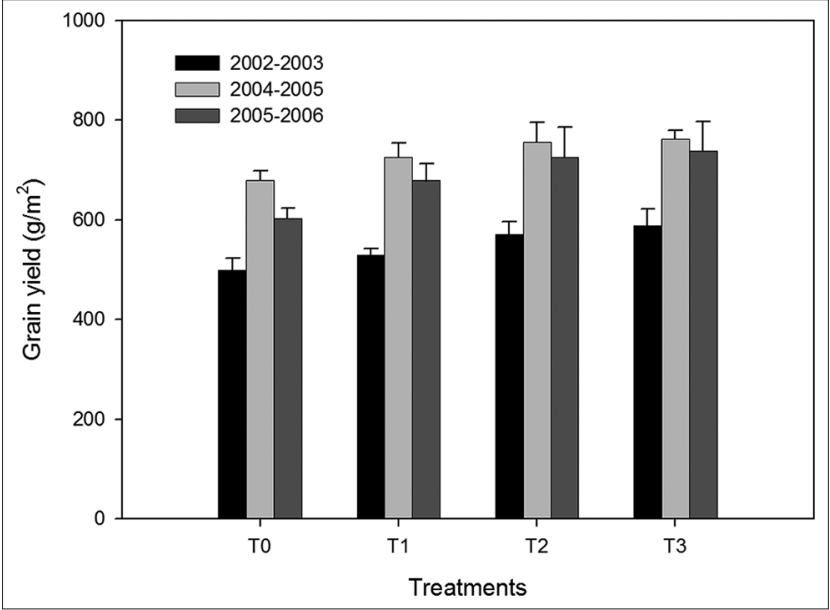

Fig 1. Winter wheat grain yield in different deficit irrigation regimes. Vertical bars are standard errors. T0, T1, T2, and T3 represent nonirrigation, irrigated $60 \mathrm{~mm}$ at JS, irrigated $60 \mathrm{~mm}$ each at JS and $\mathrm{HS}$, and irrigated $60 \mathrm{~mm}$ each at JS, HS, and MS of winter wheat, respectively. In 2002-2003 winter wheat growing season, the result was the mean results of plant 93-52 used in the experiment; in 2004-2005 and 2005-2006 growing seasons of winter wheat, the result was the mean results of plant 8049 used in the experiment.

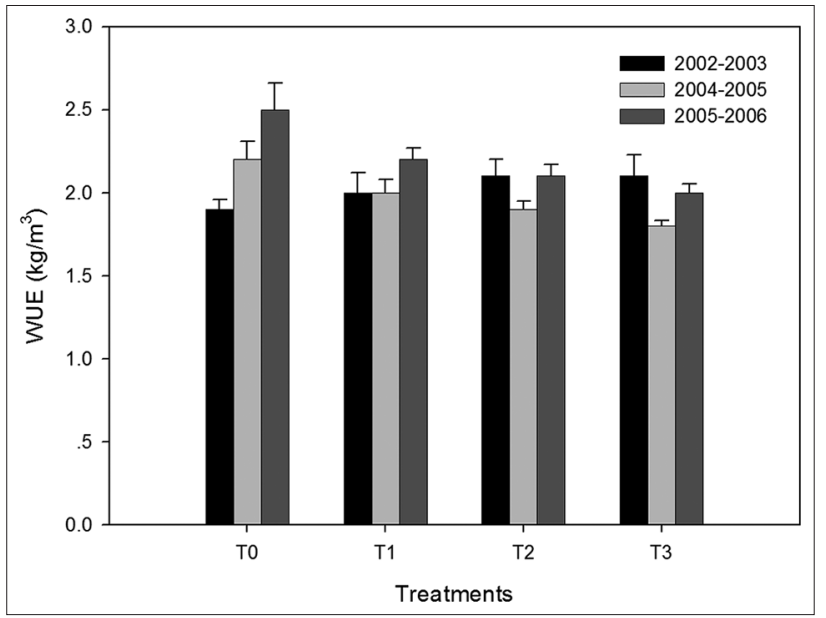

Fig 2. WUE of winter wheat in different irrigation regimes. Vertical bars are standard errors. T0, T1, T2, and T3 represent non-irrigation, irrigated $60 \mathrm{~mm}$ at JS, irrigated $60 \mathrm{~mm}$ each at JS and HS, and irrigated $60 \mathrm{~mm}$ each at JS, HS, and MS of winter wheat, respectively. In 2002-2003 winter wheat growing season, the result was the mean results of plant 93-52 used in the experiment; in 2004-2005 and 2005-2006 growing seasons of winter wheat, the result was the mean results of plant 8049 used in the experiment. 


\section{Experiment 2}

\section{Contribution of DM remobilization to grain yield}

As shown in Fig. 3, CDMRG in I2 was 54.7\% and 58.9\% in 2006-2007 and 2007-2008 growing seasons of winter wheat, which was higher than those in $\mathrm{I} 1$ and $\mathrm{I} 3$ by $3.5 \%$ and $5.1 \%$ in $2006-2007$, and by $3.6 \%$ and $2.5 \%$ in 2007-2008, respectively. This indicates that DM translated from stem and leaves to grain was much in I2 than in I1 and I3. The variation of CDMRG could affect winter wheat GY and yield components.

\section{Grain yield and yield components}

Winter wheat GY and yield components are presented in Table 2. In 2006-2007 winter wheat growing season, I2 resulted in the highest GY, was $678.29 \mathrm{~g} / \mathrm{m}^{2}$, which was significantly higher than that in I1, and the lowest GY was found in I3, which was only $409.29 \mathrm{~g} / \mathrm{m}^{2}$. The highest SN was found in I2, which was significantly higher than those in I1 and I3. Effect of irrigation frequency on kernel numbers per spike and 1000-kernel weight was not significant. In 2007-2008 winter wheat growing season, the highest GY was found in I2, it was significantly different from that in I3, and the lowest GY was found in I1, which was significantly lower than that in I2. I2 resulted in the highest SN, which was significantly higher than those in I1 and I3. As for 1000-kernel weight, I3 resulted in the highest, which was significantly higher than those in I1 and I2. Effect of irrigation frequency on kernel numbers per spike was not significant. In the both growing seasons, I2 resulted in the highest GY, which was attributed to increase $\mathrm{SN}$ significantly. Therefore, selecting suitable irrigation timing under irrigated $120 \mathrm{~mm}$ is of great importance to improve yield potential.

\section{Water use efficiency}

As shown in Fig. 4, in both 2006-2007 and 2007-2008 growing seasons of winter wheat, $\mathrm{I} 2$ resulted in the highest WUE, which was significantly higher than that in I3, and the lowest WUE was found in I1. Hence, in both dry and humid growing seasons of winter wheat, irrigated $60 \mathrm{~mm}$ each at JS and HS of winter wheat not only achieved the highest GY but also the highest WUE.

\section{DISCUSSION}

Many researchers considered that irrigation could significantly increase winter wheat GY (Ali and Seyedeh 2008; Thind et al., 2010; Kiran et al., 2008). In this experiment, the result indicated that no matter in moderate, humid, or dry growing seasons of winter wheat, irrigated $60 \mathrm{~mm}$ each at JS and HS could get the reasonable GY and WUE. With irrigation amount increased, the potential irrigation production was limited. Li et al. (2008) studied the relationship of evapotranspiration with GY and WUE of winter wheat under various conditions of irrigation

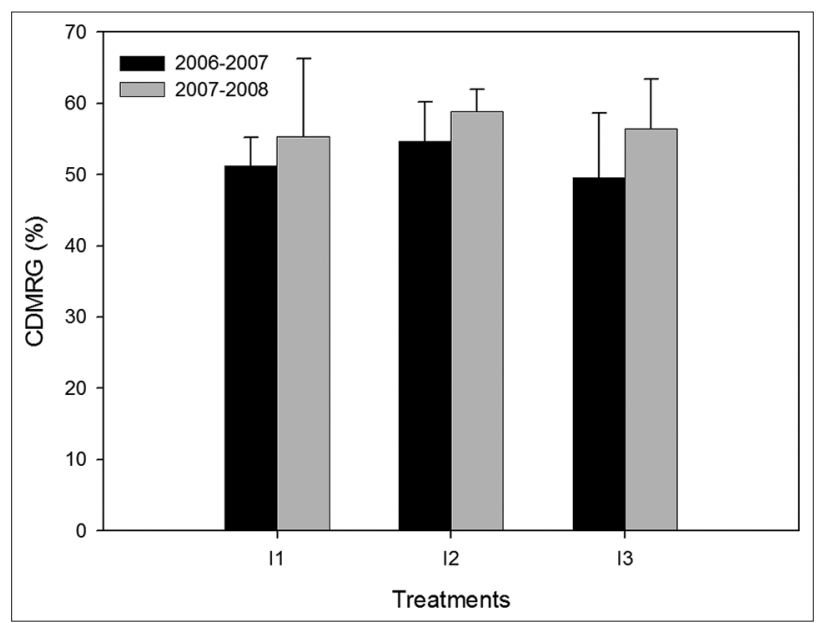

Fig 3. CDMRG of winter wheat under different irrigation frequency Vertical bars are standard errors. I1, I2, and I3 represent irrigated 120 $\mathrm{mm}$ only at JS, irrigated $60 \mathrm{~mm}$ each at JS and HS, and irrigated 40 $\mathrm{mm}$ each at JS, HS, and MS of winter wheat, respectively. The result was the mean results of plant 9204 used in the experiment.

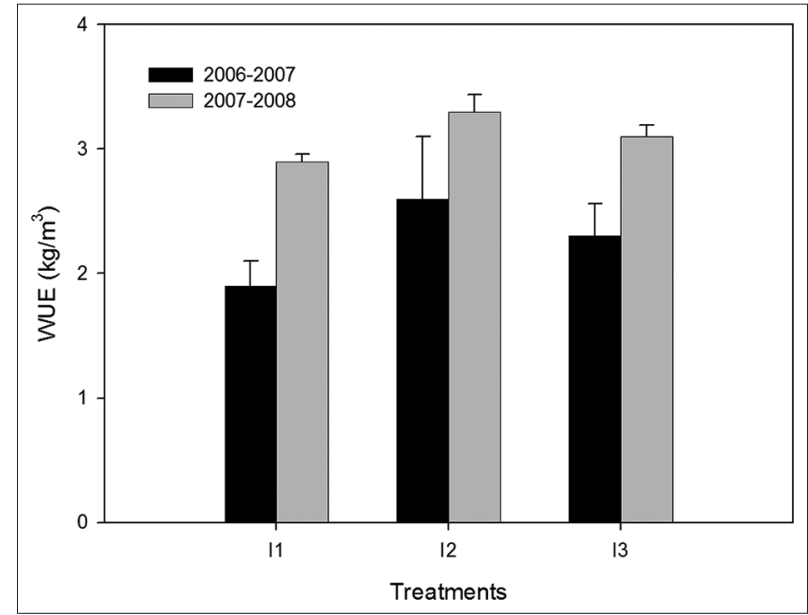

Fig 4. Effect of irrigation frequency on WUE of winter wheat. Vertical bars are standard errors. I1, I2, and I3 represent irrigated $120 \mathrm{~mm}$ only at JS, irrigated $60 \mathrm{~mm}$ each at JS and HS, and irrigated $40 \mathrm{~mm}$ each at JS, HS, and MS of winter wheat, respectively. The result was the mean results of plant 9204 used in the experiment.

and straw mulching, found that in both mulching and non-mulching conditions, the relationship between evapotranspiration and GY fit for curve of the second degree. Fang et al. (2004) indicated that photosynthesis rate, DM accumulation of population, and GY had a quadratic relationship with winter wheat water consumption, which resulted in a linear decrease on WUE at leaf and population levels and quadratic changes in WUE at yield level. In experiment 1, GY in T3 was not significantly higher than that in T2, maybe due to the GY in T3 was nearly maximum. Under the condition of full irrigation, photosynthetic rate of crops can not increase any more; however, transpiration rate sustainable increased (Fang et al., 2004). As a result, under the condition of full irrigation, crops could consume 
Table 2: Winter wheat grain yield and yield components in 2006-2007 and 2007-2008 growing seasons

\begin{tabular}{|c|c|c|c|c|c|}
\hline $\begin{array}{l}\text { Growing } \\
\text { seasons }\end{array}$ & Treatments & $\begin{array}{c}\text { Spike numbers } \\
\left(\text { spikes } / \mathrm{m}^{2}\right)\end{array}$ & $\begin{array}{c}\text { Kernel numbers per spike } \\
\text { (kernel/spike) }\end{array}$ & 1000-kernel weight (g) & Grain yield $\left(g / m^{2}\right)$ \\
\hline $2006-2007$ & $\begin{array}{l}11 \\
12 \\
13\end{array}$ & $\begin{array}{l}556.25 b \\
580.42 a \\
528.33 c\end{array}$ & $\begin{array}{l}30.71 a \\
29.41 a \\
31.61 a\end{array}$ & $\begin{array}{l}39.09 a \\
37.90 a \\
39.53 a\end{array}$ & $\begin{array}{l}557.92 b \\
678.29 a \\
409.29 c\end{array}$ \\
\hline $2007-2008$ & $\begin{array}{l}11 \\
12 \\
13\end{array}$ & $\begin{array}{c}556.27 \mathrm{~b} \\
658.05 \mathrm{a} \\
547.45 \mathrm{bc}\end{array}$ & $\begin{array}{c}29.2 \mathrm{ab} \\
30.0 \mathrm{a} \\
30.7 \mathrm{a}\end{array}$ & $\begin{array}{l}40.16 b \\
39.32 b \\
42.22 a\end{array}$ & $\begin{array}{c}699.14 a b \\
769.16 a \\
505.85 b c\end{array}$ \\
\hline
\end{tabular}

much soil water. Hence, crop transpiration has invalid water consumption (Hu et al., 2009), this is a most important reason why increasing irrigation result in low WUE.

In experiment 2, the CDMRG in $\mathrm{I} 2$ was higher than that in I3, this maybe due to the following 2 reasons: firstly, SWC could affect root length density of winter wheat significantly. Zuo et al. (2006) found that compared with surface irrigation, the root length density in sub-irrigation was higher. Under the same irrigation amount, reducing irrigation frequency could store much irrigation water in the deeper soil layer, this will aid root growth (Shao et al., 2008). Increasing root length density not only makes full use of deeper soil water but also consumes much photosynthate. Hence, the much photosynthetic product transferred to root, the less transferred to grain, which will result to decrease GY. Under field conditions, reducing photosynthetic product transferred to root is a key measure to increase crops GY. Secondly, controlled soil drying may aid to remobilize of stem-stored carbohydrate to grain. Wang et al. (2005) indicated that during rapidly remobilized stage of stored food, compared to well-watered treatments, sucrose contents of wheat stem under water deficit conditions was increased by $15.9-40.5 \%$.

In the NCP, since the 1970s, annual precipitation has been declining (Sun et al., 2010). Therefore, effective use of irrigation water is a key for sustainable development of winter wheat production. Under field conditions, crops WUE is determined by transpiration rate through leaves and water absorbing capacity through roots; hence, as for crops effective use of water in essence, is to achieve the optimum balance conditions of the structure and function of crops canopies and roots (Chen et al., 2005; Gao et al., 2007). In the NCP, as the saving water agriculture boots, to ensure the sustainable development of agriculture and effective use of water resources, it is in urgent need to study the key techniques and basic theory concerned root-shoot balance.

\section{CONCLUSIONS}

In dry and moderate growing seasons of winter wheat, GY and WUE in treatment which irrigated $60 \mathrm{~mm}$ each at JS, HS, and MS were not significantly increased, it is suggests that winter wheat should be irrigated with $60 \mathrm{~mm}$ each at JS and HS to achieve reasonable GY and WUE. Under the condition of irrigated $120 \mathrm{~mm}$ in dry and humid growing seasons of winter wheat, irrigated $60 \mathrm{~mm}$ each at JS and HS resulted in the highest CDMRG, which led to significantly increase GY and WUE. The results indicate that in the NCP, winter wheat should be irrigated $60 \mathrm{~mm}$ each at JS and HS to achieve reasonable GY and WUE.

\section{ACKNOWLEDGEMENTS}

This work was supported in part by the National Nature Science Foundation of China (31571603), and by the Funds of Shandong "Double Tops" Program (SYL2017YSTD02).

\section{AUTHOR CONTRIBUTIONS}

Quanqi Li: Conceived and designed the experiments; Huifang Han and Yujie Ren: Performed the experiments; Yujie Ren and Chao Gao: Analyzed the data; Zhenxing Yan: Contributed reagents/materials/analysis tools; Huifang Han and Quanqi Li: Wrote the paper.

\section{REFERENCES}

Abolfazl, N. and A. F. Hossein. 2007. Water use efficiency of winter wheat under deficit irrigation. J. Biol. Sci. 7: 19-26.

Ali, R. S. and N. H. Seyedeh. 2008. Effects of alternate furrow irrigation and nitrogen application rates on yield and water- and nitrogen-use efficiency of winter wheat (Triticum aestivum L.). Plant Prod. Sci. 11: 250-259.

Bartolomeo, D., X. Cristos, S. Adriano and M. Giuseppe. 2007. Effects of post333 harvest regulated deficit irrigation on carbohydrate and nitrogen partitioning, yield quality and vegetative growth of peach trees. Plant Soil 290: 127-137.

Bian, C., C. Ma, X. Liu, C. Gao, Q. Liu, Z. Yan and Q. Li. 2016. Responses of winter wheat yield and water use efficiency to irrigation frequency and planting pattern. PloS One 11(5): e0154673. doi:10.1371/journal.pone.0154673.

Blum, A. 2007. Effective use of water (EUW) and not water-use efficiency (WUE) is the target of crop yield improvement under drought stress. Field Crops Res. 112: 119-123.

Chen, X. Y., Z. H. Gao, Y. P. Luo and X. Y. Liu. 2005. Relationship between root and shoot of winter wheat under different soil water conditions and their effects on the water use efficiency. Chinese J. Eco-agr. 13: 134-137. 
Cristina, P., T. Simona and S. Orazio. 2011. Effects of deficit irrigation on biomass, yield, water productivity and fruit quality of processing tomato under semi-arid Mediterranean climate conditions. Sci. Hortic. 129: 590-596.

Dong, B. D., L. Shi, C. H. Shi, Y. Z. Qiao, M. Y. Liu and Z. B. Zhang. 2011. Grain yield and water use efficiency of two types of winter wheat cultivars under different water regimes. Agric. Water Manage. 99: 103-110.

Fang, Q. X., Y. H. Chen, Q. Q. Li, S. Z. Yu, Y. Luo, Q. Yu and Z. Ouyang. 2004. Effect of irrigation on water use efficiency of winter wheat. Trans. CSAE 20: 34-39.

Fazlullah, A., T. Bernhard and K. A. Usman. 2013. Optimizing deficit irrigation scheduling under shallow groundwater conditions in lower reaches of Amu Darya River Basin. Water Resour. Manage. 27: 3165-3178.

Gao, Z. H., X. Y. Chen and Y. P. Luo. 2007. Winter wheat root and shoot: equilibrium and growth stability under different soil and water conditions. Sci. Agric. Sinica 40: 540-548.

Guo, R. P., Z. H. Lin, X. G. Mo and C. L. Yang. 2010. Responses of crop yield and water use efficiency to climate change in the North China Plain. Agric. Water Manage. 97: 1185-1194.

He. J., Q. J. Wang, H. W. Li, L. J. Liuand H. W. Gao. 2009. Effect of alternative tillage and residue cover on yield and water use efficiency in annual double cropping system in North China Plain. Soil Till. Res. 104: 198-205.

Sun, H. Y., Y. J. Shen, Q. Yu, G. N. Flerchinger, Y. Q. Zhang, C. M. Liu and X. Y. Zhang. 2010. Effect of precipitation change on water balance and WUE of the winter wheat-summer maize rotation in the North China Plain. Agric. Water Manage. 97: 1139-1145.

Hu, T. T., S. Z. Kang, F. S. Li and J. H. Zhang. 2009. Effects of partial root-zone irrigation on the nitrogen absorption and utilization of maize. Agric. Water Manage. 96: 208-214.

Igbadun, H. E., A. A. Ramalan and E. Oiganji. 2012. Effects of regulated deficit irrigation and mulch on yield, water use and crop water productivity of onion in Samaru, Nigeria. Agric. Water Manage. 109: 162-169.

Istanbulluoglu, A., B. Arslan, E. Gocmen, E. Gezer and C. Pasa. 2010. Effects of deficit irrigation regimes on the yield and growth of oilseed rape (Brassica napus L.). Biosyst. Eng. 105: 388-394.

James, R. M., W. Andrew and P. Paxton. 2012. Deficit irrigation in a production setting: canopy temperature as an adjunct to ET estimates. Irrig. Sci. 30: 127-137.

Kiran, B. B., V. G. Sharad and K. B. Vijay. 2008. Effect of different irrigation treatments on growth and yield of wheat crop varieties. Int. J. Agric. Sci. 4: 114-118.

Li, J., S. Inanaga, Z. Li and A. E. Eneji. 2005. Optimizing irrigation scheduling for winter wheat in the North China Plain. Agric. Water Manage. 76: 8-23.

Li, Q. Q., X. B. Zhou, Y. H. Chen and S. L. Yu. 2010. Grain yield and quality of winter wheat in different patterns under deficit irrigation regimes. Plant Soil Environ. 56: 482-487.

Li, Q. Q., Y. H. Chen, M. Y. Liu, X. B. Zhou, S. L. Yu and B. D. Dong. 2008. Effect of irrigation and straw mulching on microclimate characteristics and water use efficiency of winter wheat in North China. Plant Prod. Sci. 11: 161-170.

Li, Q. Q., K. Lang, Q. R. Liu, C. Y. Bian, X. H. Liu and G. Q. Chen. 2013. Dry matter, grain yield, and evapotranspiraiton of winter wheat under deficit irrigation in North China Plain. J. Food Agric. Environ. 11: 2593-2596.

Mo, X., S. Liu, Z. Lin and R. Guo. 2009. Regional crop yield, water consumption and water use efficiency and their responses to climate change in the North China Plain. Agric. Ecosyst. Environ.
134: $67-78$.

Nader, K., M. Marcello and E. C. Houssem. 2010. Effects of corn deficit irrigation and soil properties on water use efficiency. A 25year analysis of Mediterranean environment usting the STICS model. Eur. J. Agron. 32: 177-185.

Neal, J. S., W. J. Fulkerson and B. G. Sutton. 2011. Differences in wateruse efficiency among perennial forages used by the dairy industry under optimum and deficit irrigation. Irrig. Sci. 29: 213-232.

Neal, J. S., S. R. Murphy, S. Harden and W. J. Fulkerson. 2012. Differences in soil water content between perennial and annual forages and crops grown under deficit irrigation and used by the dairy industry. Field Crops Res. 137: 148-162.

Rao, S. S., P. L. Regar, S. P. S. Tanwar and Y. V. Singh. 2013. Wheat yield response to line source sprinkler irrigation and soil management practices on medium-textured shallow soils of arid environment. Irrig. Sci. 31: 1185-1197.

Romulus, O. O., R. P. Troy, L. R. Kerry, B. W. Douglas and R. Maria. 2012. Impact of sustained deficit irrigation on spearmint (Mentha spicata L.) biomass production, oil yield, and oil quality. Irrig. Sci. 30: 213-219.

Shao, L. W., X. Y. Zhang, S. Y. Chen, H. Y. Sun and Z. H. Wang. 2008. Effects of irrigation frequency under limited irrigation on root water uptake, yield and water use efficiency of winter wheat. Irrig. Drain. 58: 393-405.

Soundharajan, B. and K. P. Sudheer. 2009. Deficit irrigation management for rice using crop growth simulation model in an optimization framework. Paddy Water Environ. 7: 135-149.

Thind, H. S., G. S. Buttar and M. S. Aujla. 2010. Yield and water use efficiency of wheat and cotton under alternate furrow and checkbasin irrigation with canal and tube well water in Punjab, India. Irrig. Sci. 28: 489-496.

Tian, S. Z., T. Y. Ning, H. X. Zhao, B. W. Wang, N. Li, H. F. Han, Z. J. $\mathrm{Li}$ and S. Y. Chi. 2012. Response of $\mathrm{CH}_{4}$ and $\mathrm{N}_{2} \mathrm{O}$ emissions and wheat yields to tillage method changes in the North China Plain. Plos One 7(12): e51206. doi:10.137/journal.pone.0051206.

Wang, H. Q., F. L. Liu, N. A. Mathias and R. J. Christian. 2009. Comparative effects of partial root-zone drying and deficit irrigation on nitrogen uptake in potatoes (Solanum tuberosum L.). Irrig. Sci. 27: 443-448.

Wang, W., Y. X. Cai, J. H. Zhang, J. C. Yang and Q. S. Zhu. 2005. Regulation of controlled soil drying on remobilization of stemstored carbohydrate to grain in wheat grown under unfavorablydelayed senescence. Acta Agron. Sinica 31: 289-296.

Wu, K., B. Lu and Z. Yuan. 2006. The recent developments and the contribution of farmland irrigation to national grain safeness in China. J. Irrig. Drain. 25: 7-10.

Xue, Q., Z. Zhu, J. T. Musick, B. A. Stewart and D. A. Dusek. 2003. Root growth and water uptake in winter wheat under deficit irrigation. Plant Soil 257: 151-161.

Zhang, B. C., F. M. Li, G. B. Huang, Z. Y. Cheng and Y. H. Zhang. 2006. Yield performance of spring wheat improved by regulated deficit irrigation in an arid area. Agric. Water Manage. 79: 28-42.

Zhao, D. D., J. Y. Shen, K. Lang, Q. R. Liu and Q. Q. Li. 2013. Effects of irrigation and wide-precision planting on water use, radiation interception, and grain yield of winter wheat in the North China Plain. Agric. Water Manage. 118: 87-92.

Zhou, X. B., Y. H. Chen and Z. Ouyang. 2011. Effects of row spacing on soil water and water consumption of winter wheat under irrigated and rainfed conditions. Plant Soil Environ. 57: 115-121.

Zuo, Q., J. C. Shi, Y. L. Li and R. D. Zhang. 2006. Root length density and water uptake distributions of winter wheat under subirrigation. Plant Soil 285: 45-55. 